\title{
Development of the Mediterranean Soup for Enteral Nutrition and for Prevention of Cardiovascular Diseases
}

\author{
R.B. Singh ${ }^{1, *}$, Jayeeta Choudhury ${ }^{2}$, Fabien De Meester ${ }^{3}$ and D.W. Wilson ${ }^{4}$ \\ ${ }^{1}$ Halberg Hospital and Research Institute, UP, India \\ ${ }^{2}$ Center of Nutrition Research, Ahmedabad, Gujarat \\ ${ }^{3}$ The Tsim Tsoum Institute, Krakow, Poland \\ ${ }^{4}$ School of Medicine and Health, Durham University, UK
}

\begin{abstract}
Background: The Paleolithic diet with fruits, vegetables, roots, leaves, seeds, honey, meat, fish and eggs provided low w-6/w-3 ratio of fatty acids, high monounsaturated fatty acids, fiber, phytochemical antioxidants and proteins. Recent studies indicate that diets similar to Paleolithic diet have anti-inflammatory potential, whereas Western diet, with refined carbohydrates, high w-6/w-3 ratio of fatty acids, lower protein, high in saturated trans and w-6 fat, has proinflammatory effects.

Foods that comply with the Paleolithic diet promote a balanced ratio of omega-6 and omega-3 fatty acids (w6:w3-PUFAs $=1: 1$ ) in serum total lipids and, in turn, a $25 \%$ proportion of $\mathrm{w}-6$ in blood total highly unsaturated fatty acids (HUFAs). Further evidence suggest that walnuts and almonds can decrease heart disease risk due to their hypolipidemic and antiinflammatory effects. Such diet can also enhance immunity and adaptation due to decrease in inflammation. A metaanalysis of prospective cohort studies demonstrated that an increased consumption of fruit and vegetables from less than 3 to more than 5 servings / day is related to a $17 \%$ reduction in CAD risk, whereas an increased intake from 3 to 5 servings/day is associated with a smaller and borderline significant reduction. These results provide evidence supporting that 5 or more servings per day of fruit and vegetables, are needed to protect from noncommunicable diseases in general, and cardiovascular diseases (CVDs) in particular. There is evidence that a Mediterranean diet (fruits, vegetables, nuts, olive oil, whole grains) and Indo-Mediterranean diets (whole grains and mustard oil, vegetable, fruits and nuts) may be protective in patients with high risk of CVD. In some of these studies, soup rich in nuts, raisins, vegetables, tomato, carrot and mustard oil+olive oil as well as yogurt containing nuts and raisins have been used in the treatment of acute coronary syndrome, resulting into significant reduction in cardiac events and mortality.
\end{abstract}

Keywords: Paleolithic diet, fruits, vegetables, nuts, whole grains, heart disease.

\section{INTRODUCTION}

Prior to the Agricultural Revolution, our diet was based on wild plants, seeds, eggs, fish and meat from wild animals, whereas the latter half of the 20th century saw major changes to daily diets, moving from plant-based diets to high-fat, animal-based diets. Today, the greatest percentage of food supply is contributed by cereal grains, (mainly refined), refined carbohydrates and meat from farm sources [1-4]. The recent unacculturated native populations that moved to a modern Western lifestyle (and diet) are on foods rich in w-6 fatty acids, saturated fat and trans fat and low in w-3 fatty acids, fiber, phytoestrogens, minerals and antioxidants. In fact, the Agricultural Revolution (starting about 10,000 years ago) and the Industrial Revolution (onset a couple centuries ago) have produced an environment vastly different from

*Address correspondence to this author at the Halberg Hospital and Research Institute, Civil Lines, Moradabad-10(UP)244001, India;

Tel/Fax: 0091591 2417437;

E-mailsicn2005@bsnl.in,rbs@tsimtsoum.net that of our Paleolithic ancestors, different from what Homo sapiens were thriving in for probably hundreds of thousands of years. This discordance has resulted in an ageing population, central obesity, sedentary lifestyle, excessive salt and alcohol, lower fruit, vegetable and legumes intake, increased risk for blood pressure elevation [5], type 2 diabetes, atherosclerosis, and some cancers. Cardiovascular disease (CVD), diabetes mellitus, obesity, cancer, autoimmune diseases, rheumatoid arthritis, asthma and depression are associated with increased production of thromboxane A2(TXA2), leucotrienes, protacyclin, interleukins-1 and 6, tumor necrosis factor-alpha and C-reactive proteins [1-3]. Increased dietary intake of $\mathrm{w}-6$ fatty acids is known to enhance all these risk factors as well as atherogenicity of cholesterol which have adverse proinflammatory effects resulting into thrombosis and acute coronary syndromes (ACS) [1-3].

Foods that comply with the Columbus Concept promote a balance ratio of omega- 6 and omega-3 fatty acids (w6:w3PUFAs $=1: 1$ ) in serum total lipids and, in turn, a $25 \%$ 
proportion of w-6 in blood total highly unsaturated fatty acids (HUFAs) [1-4]. Recent studies [6-9] indicate that walnuts and almonds can decrease CVD risk due to their hypolipidemic and anti-inflammatory effects. A metaanalysis of prospective cohort studies demonstrated that an increased consumption of fruit and vegetables from less than 3 to more than 5 servings / day is related to a $17 \%$ reduction in CAD risk, whereas an increased intake from 3 to 5 servings/day is associated with a smaller and borderline significant reduction. These results provide evidence supporting that 5 or more servings per day of fruit and vegetables, are needed to give a measure of protection from CVD [10-18]. There is evidence that a Mediterranean diet (fruits, vegetables, nuts, olive oil, whole grains) and IndoMediterranean diets (whole grains and mustard oil, vegetable, fruits and nuts) may be protective in patients with high risk of CVD [10-18]. In some of these studies, soup rich in nuts, raisins, vegetables and mustard oil as well as yogurt containing nuts and raisins have been used in the treatment of ACS, resulting in significant benefit [14-16].

Western diet is characterized with energy dense, refined, ready-prepared foods with a high glycemic index (e.g., refined starches; bread, biscuits, candies, cornflakes, pizza, potato chips, cola drinks and sugar) and unhealthy lipids (e.g., TFA, SF, omega- 6 rich oils) and poor in phytochemicals and fiber. Such diets have been adopted by an increased number of people and populations in the Western world and in the urban populations of middle income countries in the last few decades. These diets are known to predispose the epidemic of CVD and diabetes [1-4, 19-22] in the last two decades in all developing countries. Insulin resistance appears to be a risk factor of Type 2 diabetes, hypertension and CAD even among South Asians [23, 24].

\section{WESTERN DIET AND DEVELOPMENT OF DISEASES}

Meal absorption is a complex phenomenon, and post-prandial hyperlipidaemia, and hyperglycaemia are simultaneously present in the post-absorptive phase, particularly in type 2 diabetic patients or in subjects with impaired glucose tolerance including obesity [18-22]. Both post-prandial hyperglycaemia and hypertriglyceridaemia may cause endothelial dysfunction, which is considered an early marker of atherosclerosis $[18,19,25]$. Endothelial dysfunction is also observed in conditions associated with sedentary lifestyle, and the metabolic syndrome [26-28]. The effect of different isocaloric meals on endothelial function in both normal subjects and type 2 diabetic patients may be that the level of triglycerides after a high-fat (saturated) meal are associated with endothelial dysfunction, with maximal impairment occurring at the time of the simultaneous presence of post-prandial hyperglycaemia and hypertriglyceridaemia [25]. The effect of liquid meals rich in carbohydrates or saturated fats may be similar. It is possible that endothelial dysfunction is induced by high-fat meals in type 2 diabetic patients or associated with fasting hypertriglyceridaemia in young men and could be associated with increased plasma concentrations of asymmetric dimethylarginine, an endogenous nitric oxide synthase inhibitor, suggested as a novel cardiovascular risk factor.

Further proof for the Columbus ${ }^{\circledR}$ concept was provided in more recent studies on the effect of meals on risk factors of atherothrombosis. Consumption of high-fat meals and vegetable foods rich in natural antioxidants largely prevent the negative effects on endothelial function [25]. In particular, endothelial dysfunction acutely triggered by the consumption of a high-fat meals rich in saturated fatty acids is reduced by the simultaneous consumption of a vegetable serving which includes pepper $(100 \mathrm{~g})$, tomatoes (100 g), and carrots (200 g). A mild pro-oxidative state accompanies meal ingestion, which results in raised circulating biomarkers of inflammation, adhesion, and endothelial dysfunction, all of which are factors in the development of cardiovascular disease. The effect of hyperglicaemia, hypertriglyceridaemia, and raised FFA levels, both fasting and post-prandial, on endothelial function may be mediated through the generation of an oxidative stress. The process is supposed to involve increased super-oxide generation, which in turn inactivates nitric oxide. Superoxide and nitric oxide combine to produce peroxynitrite, a potent and long-lived oxidant that is cytotoxic, initiates lipid peroxidation, and nitrates amino acids such as tyrosine that affect many signal transduction pathways. The production of the peroxynitrite anion can be indirectly inferred by the presence of nitrotyrosine (NT). An increase in plasma NT levels has been reported in association with postprandial hyperglycaemia or hypertriglyceridaemia, with a cumulative effect occurring in the presence of both conditions. It seems therefore that oxidative stress is a mediator of the effect of raised substrate concentration in the post-prandial phase. It is clear that what happens during the absorption phase may be of considerable importance because it occurs several times each day and human beings now spend an increasingly greater part of their lives in the post-prandial phase without periods of fasting. These biological markers after high-fat meals also rich in refined carbohydrates appear to be basic underlying mechanisms for insulin resistance and CVD.

\section{PROINFLAMMATORY MACRONUTRIENTS}

Proinflammatory macronutrients such as $\omega-6$ fatty acids, TFA, and SFA, as well as refined carbohydrates intake may produce oxidative stress and proinflammatory substances [25]. Glucose ingestion in normal subjects is associated with increased superoxide generation in leukocytes and mononuclear cells, as well as with raised amount and activity of nuclear factor- $\mathrm{kB}(\mathrm{NF}-\mathrm{k} \beta)$, a transcriptional factor regulating the activity of at least 125 genes, most of which are pro-inflammatory [25]. The cytokine hypothesis presently suggests that an excessive production of proinflammatory cytokines, such as tumour necrosis factor alpha (TNF) and interleukin 6 (IL6), even contributes to the pathogenesis of heart failure [29]. Increased consumption of refined carbohydrates also causes an increase in two other pro-inflammatory transcription factors: (i) activating protein1(AP-1) and (ii) Egr-1. The first regulated the transcription of matrix metalloproteinases and the second modulates the transcription of tissue factor and plasminogen activator inhibitor-1. A mixed meal from a fast-food chain has also been shown to induce activation of NF-k $\beta$ associated with the generation of reactive oxygen species (ROS) by mononuclear cells. Superoxide anion appears to be an activator of at least two major pro-inflammatory transcription factors, NF-k $\beta$ and AP-1. These observations are consistent with previous findings, demonstrating that after oral or 
intravenous glucose challenges, in both normal subjects and patients with type 2 diabetes mellitus, there is an increased generation of ROS and raised circulating levels of proinflammatory cytokines, such as TNF-alpha, IL-6, and IL-18 [19-22,25]. In apparently healthy subjects, a single high-fat meal produced endothelial activation, as evidenced by increased concentrations of the adhesion molecules vascular cell adhesion molecule-1 (VCAM-1) and intercellular adhesion.

\section{CARDIOPROTECTIVE AND PROINFLAMMATORY DIETS}

The vascular effects of high sugar and high fat meals have greatly increased our understanding about the role of diet on atherothrombosis. There is an increased flux of nutrients in the post-prandial state which is associated with an increase in circulating levels of proinflammatory cytokines, recruitment of netrophils, and oxidative stress. The generation of ROS may be a common ground for all these findings and may help in the understanding of current dietetic recommendations from the International College of Cardiology, emphasizing increased consumption of fruits, vegetables $(400 \mathrm{~g} / \mathrm{d})$, nuts $(50 \mathrm{~g} / \mathrm{d})$, grains $(400 \mathrm{~g} / \mathrm{d})$, and spices. These foods are rich in natural antioxidants, phytochemicals, and fiber that help fight the oxidant wave of meals. Decreasing the intake of trans- and saturated fatty acids and increasing the consumption of $\omega$-3 fatty acids (e.g., flax seed, mustard, and canola oil) and MUFAs (e.g., olive oil) are also considered important strategies to reduce CAD and metabolic syndrome [1-3]. There is evidence that these two strategies are also associated with a reduced inflammatory status. Further, recent publication in FSAEB Journal results also showed that the consumption of virgin olive oil in conjunction with a Mediterranean diet can positively impact lipid and DNA oxidation, insulin resistance, inflammation, carcinogenesis, and tumor suppression [30]. In the Nurse's Health Study, levels of C-reactive protein and markers of endothelial dysfunction were $73 \%$ higher in the highest quintile of TFA intake, compared with the lowest quintile. and low-cholesterol/low-saturated fat diets are associated with mitigation of low-grade systemic inflammation which correlated with reduction of plasma C-reactive protein levels. Cross-sectional study from the Nurse's Health Study I cohort demonstrated lower concentrations of many markers of inflammation and endothelial activation, including C-reactive protein, IL-6, and E-selectin, among those in the highest quintile of $\omega-3$ fatty acids, when compared with the lowest quintile.

Omega - 3 Fatty acids exert pleiotrophic cardiometabolic effects with diverge range of actions [31]. Epidemiology and epidemiological studies in the last 40years suggest beneficial effects of w-3 FA derived from fish and fish oil on many CVD end points, including all CVD (defined as all coronary artery disease (CAD), fatal and non fatal myocardial infarction and stroke combined ) all CAD fatal and non fatal stroke, sudden cardiac death and all cause of mortality [32, 33]. The consumption of w-3 PUFA has also been reported to decrease resting heart rate (HR) and increase heart rate variability (HRV) [34, 35]. Compared with modest fish intake of once aweek or $20 \mathrm{~g}$ per day, a higher intake was associated with substantially reduced risk of coronary heart disease, primarily non-fatal cardiac events among middle aged persons [36]. Cardioprotective effects have been observed with daily consumption of as little as $25-75 \mathrm{~g}$ (approximately (1-2 oz) of fish high in marine derived w-3 $\mathrm{FA}$, an intake equivalent to $>$ or $1=$ fish meal weekly or monthly upto serving per week [33]. The beneficial effects of high doses of w-3 FA includes ability to reduce TG levels, blood pressure, platelet aggregation, arrhythmia, atherogenesis and effects on immunological responses [32, 37]. US Food and Drug administration and US environmental Protection agency discussed current dietary and safety recommendation of fish and fish oil capsules. The general public is recommended to consume 2 fatty fish meals per week $(0.3-0.5 \mathrm{~g}$ per day eicosapentanoic acid and docosapentanoic acid); patient with coronary heart disease should have $1 \mathrm{~g}$ per day of EPA and DHA, whereas TG patients with hypertriglycerides should take 3-5g /day EPA and DHA under physician's advise [37]. Stabilisation of cell membranes and suppression of cardIac arrhythmias have been identified as possible mechanisms. The w-3 index (erythrocyte EPA plus DPA) may be considered as a potential risk marker for coronary heart disease mortality, especially sudden cardiac death. However, balance of n-6 to n-3 FA is important determinant in deceasing the risk for CHD, both in primary and in the secondary prevention of coronary heart disease [38].

Even, Plant-derived $\alpha$-linolenic acid (ALA) may constitute an attractive cardioprotective alternative to fishderived $n-3$ fatty acids however, the effect of dietary ALA on arterial thrombus formation remains unknown. Arterial thrombus formation was delayed in mice (Male C57B1/6 mice) fed a high-ALA diet compared with those on a lowALA diet. Dietary ALA impaired platelet aggregation to collagen and thrombin and decreased p38 mitogen-activated protein kinase activation in platelets. Dietary ALA impaired arterial tissue factor (TF) expression, TF activity, and nuclear factor- $\kappa \mathrm{B}$ activity; plasma clotting times and plasma thrombin generation did not differ. In cultured human vascular smooth muscle and endothelial cells, ALA inhibited $\mathrm{TF}$ expression and activity. Inhibition of $\mathrm{TF}$ expression occurred at the transcriptional level via the mitogen-activated protein kinase p38 in smooth muscle cells and p38, extracellular signal-regulated kinases 1 and 2, and c-Jun Nterminal kinases 1 and 2 in endothelial cells. ALA represents an attractive nutritional intervention with direct dual antithrombotic effects [39].

Because a high intake of $\omega-6$ fatty acids may reduce the known beneficial effects of $\tilde{\omega} 3$ fatty acids on CAD risk [13]; a combination of both types of fatty acids in a ratio of $1: 1$ as advised by Columbus Paradigm Institute, which may be associated with the lowest level of inflammation [25]. ( www.columbus concept.com) However, it seems that $\omega-6: \omega-$ 3 ratio in the diet should be $<5.0$ to have optimal benefit of these fatty acids in the prevention of CVD, type 2 diabetes and CVD.

Because free radical stress is supposed to play a key role in the development of atherosclerosis, antioxidant-vitamin supplementation has been suggested for the treatment and prevention of chronic diseases, including CAD [6, 40-44]. The encouraging results of short-term trials in participants with coronary atherosclerosis were not confirmed in large- 
size intervention trials. It appears that it is wrong to focus on a single element of the diet. Guidelines from some professional or governmental panels recommend consumption of phytochemicals and minerals from food sources rather than from supplements [25]. A shift toward energy dense, refined, ready prepared foods with a high glycemic index (e.g., refined starches and sugar) and unhealthy lipids (e.g., TFA, SF, 7-6 rich oils) and poor in phytochemicals and fiber have been adopted by increased number of people and populations in the Western world and in the urban populations of middle income countries in the last few decades. These changes in diet can cause inactivation of innate immune system through excessive production of proinflammatory cytokines and reduced production of anti-inflammatory cytokines that may result in generation of inflammatory milieu, causing insulin resistance and endothelial dysfunction. These changes in diet, in conjunction with inadequate physical activity, appear to be responsible for the development of positive energy balance, weight gain, and central obesity, which is widely acknowledged as an endocrine organ secreting an increased number of mediators, including proinflammatory cytokines. Central obesity is a key promoter of low-grade systemic inflammation [25-48] and is characterized by the most severe metabolic abnormalities. It seems that subjects with abdominal adiposity are particularly prone to the proinflammatory effects of unhealthy diets [45-48]. The changes in dietary patterns that have occurred in recent years are characterized by the intake of large amount of foods that are faster to prepare and produce health damage. One prospective Coronary artery risk development in young adults (CARDIA) study indicated that frequent fast food intake caused weight gain and the risk of insulin resistance over a period of $15 \mathrm{yr}$. The Quebec Family Study showed that a decrease in the consumption of fat-foods or an increase in consumption of whole fruits resulted in a lower increase in body weight and adiposity indicators over a 6-yr follow-up. Researchers at University Hospital in Basel, Switzerland systematically identified randomized controlled trials comparing Mediterranean to low-fat diets for overweight or obese subjects. Only those studies with a minimum followup of six month, and that included data on cardiovascular risk factors were included. The researchers concluded that, in the six studies examined, people assigned to the Med Diet group showed more weight loss, lower BMI, lower blood pressure, better blood sugar control, reduced cholesterol, and lower C-reactive protein than those following a low-fat diet in these interventions [49]. However, no specific dietary recommendations have been advocated by health agencies for the treatment of insulin resistance or the metabolic syndrome. Reports suggest that High monounsaturated to saturated fatty acid intake showed a protective effect on insulin resistance [50]. Given that metabolic syndrome is an identifiable and potentially modifiable risk state for both type 2 diabetes and cardiovascular disease, adopting a healthy dietary pattern may reduce the potential risk of these diseases. Treatment with diets rich in MUFA and omega-3 fatty acids, meditation, beta blockers, ACE inhibitors, and phytochemicals may have a beneficial influence on insulin receptors and ventromedial hypothalamic dysfunction, causing beneficial effects in metabolic syndrome [4]. Several components of Mediterranean diet patterns have been inversely related with body mass index. They are considered to be modulators of insulin resistance, can exert beneficial effects on blood pressure, improve atherogenic dyslipidemia or attenuate the inflammatory burden associated with metabolic syndrome [29]. In Mediterranean- style dietary pattern score (MSDPS) in Framingham Heart study offspring Cohort study involving 2730 patients showed an association with lower insulin resistance, waist circumference, fasting plasma glucose and triglycerides and high HDL cholestrol thus showing protective effect against metabolic syndromes [51, 52]. Recently, to assess the Mediterranean Diet's effect on metabolic syndrome, scientists in Greece and Italy conducted a meta-analysis of 50 peer-reviewed Mediterranean Diet studies (including 35 clinical trials) involving more than half a million people. The researchers found that the Med Diet improved all five risk factors, and overall reduced the risk of Metabolic Syndrome. They concluded that "this dietary pattern can be easily adopted by all population groups and various cultures, and costeffectively serve for primary and secondary prevention of Metabolic Syndrome and its individual components [53, 54]. A 2011 meta-analysis published in Journal of American College of cardiology analysed the results of 50 studies (35 clinical trials, 2 prospective and 13 cross- sectional) covering about 535000 people to examine the effect on metbolic syndrome and concluded that mediterranean diet is associated with lower blood pressure, blood sugar and triglycerides [54].

Dietary pattern consisting of high intakes of vegetables, fruits, legumes, fish, poultry, and whole grains, can be protective against mortality from cardiovascular and malignant diseases. A meta-analysis of prospective cohort studies demonstrated that an increased consumption of fruit and vegetables from less than 3 to more than 5 servings/day is related to a $17 \%$ reduction, whereas an increased intake from 3 to 5 servings/day is associated with a smaller and borderline significant [55] reduction in CAD risk. Decreased heart rate variability, increased blood pressure variability, dyslipidemia, increased IL-6, IL-1, TNF-alpha, C-reactive protein, and adhesion molecules are other important determinants of mortality in patients of heart failure [56]. Nutritional factors such as increased consumption of proinflammatory foods; refined starches and sugar, trans fatty acids, w- 6 fatty acids, and saturated fat may enhance proinflammatory cytokines. Therefore eating proinflammatory foods could be an important cause of increased mortality in heart failure, because these patients have a pre-existing proinflammatory milieu. These foods may produce oxidative stress, free fatty acids, and proinflammatory substances, which result in endothelial dysfunction [56]. Knoops et al., [11], demonstrated that in European men and women between the ages of 70 and 90, who adhered to a Mediterranean-style diet representing a solid example of a healthy dietary pattern (e.g., moderate alcohol consumption, nonsmoking status, and physical activity) was associated with a lower rate of all-cause mortality. A healthy lifestyle is very important to prevent many chronic diseases. Mediterranean Diet correlates with reduced risk of death from all causes, healthy weights and cardiac health [57]. Researchers found that people who stuck strictly to a Mediterranean Diet had significant improvement intheir health including $9.1 \%$ drop in overall mortality and 
$9 \%$ drop in mortality from cardiovascular disease [58]. This combination of healthy diet and lifestyle was associated with a mortality rate of about one-third that of those with none or only one of these protective factors. A greater adherence to the Mediterranean diet, as reflected by a higher Alternate Mediterranean Diet Score, was associated with a lower risk of incident CHD and stroke in women [53]. In another larger study, involving about 22,000 adults, showed an inverse correlation between adherence to a Mediterranean-style diet and death [12]. In particular, an approximate 2/9 fold increase in Mediterranean diet score was associated with a $25 \%$ reduction in total mortality and a $33 \%$ reduction in CHD mortality. Two main intervention trials that adhered to the whole diet approach also supported this epidemiological evidence. In the Lyon Diet Heart Study, [13] 605 patients who had myocardial infarction were randomly assigned to a "Mediterranean-style" diet or a control diet resembling the American Heart Association Step I diet. The Mediterranean diet model supplied $30 \%$ of energy from fats and $<10 \%$ of energy from saturated fatty acids, whereas the intake of 18:3 (n-3) (<-linolenic acid) provided $>0.6 \%$ of energy. After a mean follow-up of 27 mo, the risk of new acute myocardial infarction and episodes of unstable angina was reduced by $\sim 70 \%$ by the Mediterranean diet, Moreover, total mortality was also reduced by $70 \%$. Singh et al., [14] tested an "IndoMediterranean diet" in 1000 patients in India who had existing coronary disease or were at high risk for developing coronary disease. When compared with the control diet, the intervention diet-characterized by increased intake of mustard or soyabean oil, nuts, vegetables, fruits, and whole grains-reduced the rate of fatal myocardial infarction by one-third and the rate of sudden death from cardiac causes by two-thirds. A new meta-analysis showed that a 2-point increase in adherence to the Mediterranean diet was associated with a significant reduction of overall mortality [relative risk $(\mathrm{RR})=0.92 ; 95 \% \mathrm{CI}: 0.90,0.94$ ], cardiovascular incidence or mortality ( $\mathrm{RR}=0.90$; 95\% CI: 0.87, 0.93), cancer incidence or mortality $(\mathrm{RR}=0.94 ; 95 \% \mathrm{CI}: 0.92$, $0.96)$, and neurodegenerative diseases ( $\mathrm{RR}=0.87$; 95\% CI: $0.81,0.94)$ [59]. Researchers analyzed data on lifestyle factors of 81,722 women who participated in the Nurses' Health Study from June 1984 to June 2010. A low -risk factors were assessed. A low - risk lifestyle was defined (not smoking, BMI $<25$, exercise duration of $30 \mathrm{miin} /$ day) and on top $40 \%$ of the alternate Mediterranean diet score, emphasizes high intake of vegetables, fruits, nuts, legumes, wholegrains, fish and moderate intake of alchohol. Overall, there were 321 cases of sudden cardiac death among women during 26 years of follow-up. Each healthy habit conferred a lower risk of sudden cardiac disease on its own, but risk for sudden cardiac death (SCD) was lowest among women who followed all four options of the healthy lifestyle [60].

Mediterranean diet is rich in phytosterol containing plant foods. Comparision of 106 high cardiovascular high risk subjects assigned to receive either Mediterranean diet (virgin oil/ nuts) or low fat diet, showed that with increased intake of fibre, PUFA and phytosterols was associated with significant reduction in LDL-C and LDL/HDL ratio [61]. Acute coronary syndromes(ACS) is associated with hyperglycemia, hypertriglyceridemia, hyperinsulinemia, increased free fatty acids (FFA), free radical stress, IL-6, TNF-alpha which are also indicators of metabolic syndrome and CVD.
There is deficiency of antioxidant vitamins and omega-3 fatty acids, among ACS patients which appears to be responsible for complications and deaths. Recent studies indicate that eating high-fat, refined carbohydrate-rich fast foods (Western diet) can produce a similar proinflammatory state in our body, resulting in endothelial dysfunction, which may have adverse effects in patients with ACS [25]. Results of a randomized, controlled trial of cardioprotective diet in 505 patients with acute myocardial infarction who were assigned to diet within 24-48 hours of infarction reported that - if comprehensive dietary changes ( low fat diet and to eat more of fruits, vegetables, nuts and grain products) in conjunction with weight loss immediately after acute myocardial infarction is followed - then it may modulate blood lipoprotein and significantly reduce complications and mortality after 1 year [23]. It is therefore, logical to avoid the Western diet in patients with ACS and administer IndoMediterranean foods which may be beneficial to vascular endothelium and myocardium by decreasing inflammation. Further studies also show that when adults were shifted from a Western-type diet to combined low fat, low cholesterol, Mediterranean type diet (LFCMD), a decrease in plasma LDL-C due to Mediterranean type diet occurred in low absorbers of cholesterol [62]. Greater adherence to the Mediterranean diet seems to preserve left ventricular systolic function and is associated with better long-term prognosis of patients who have had an ACS. During the hospital stay, those in the highest third of Mediterranean diet score had lower in-hospital deaths (compared with the lower third scores) ( $\mathrm{P}=0.009)$. Chrysohoou, $\mathrm{C}$., et al., reported that the Mediterranean diet contributes to the preservation of left ventricular systolic function and to the long-term favorable prognosis of patients who have had an acute coronary event [63].

Recent studies indicate nuts may reduce the risk of CHD by lowering total and LDL cholesterol, reducing proinflammatory cytokines, [64-66] decreasing oxidative stress, improving endothelial function, decreasing the risk of type 2 diabetes (in women), and reducing the risk of weight gain [67]. An analysis of four major cohort studies (the Adventist Health Study, the Iowa Women's Health Study, the Nurses' Health Study, and the Physicians' Health Study) found that subjects with the highest intake of nuts (five servings per week) had a $37 \%$ lower risk of death from CHD. Each weekly serving of nuts reduced the risk of CHD death by $8.3 \%$. The cardiovascular benefits of nut consumption are also similar for different clinical outcomes: non-fatal myocardial infarction, fatal CHD, and sudden cardiac death. The findings are the same regardless of sex, age, geographic location, and occupation [68]. There is no precise and proven, guideline for dietary advice, in patients with ACS, which may be protective against recurrent cardiac events. A Columbus soup (tomatoes, grapes, vegetables, walnuts, almonds+linseed and olive oil) or yogurt containing walnuts, almonds, raisins, could be prepared for ready-use, for non-pharmacological intervention, among patients with ACS.

\section{STANDARD VEGETABLE SOUP}

There is no serious consideration of nutrient content of foods in making other vegetable soups, except for dietary 
cholesterol and saturated fat which is outdated. The soups are of vegetable origin but may have excess of saturated and trans fat without any consideration of w-6:w-3 fatty acid ratio and phytochemicals. The effect of soup on glycemia, HDL-C and other lipids and on oxidative stress and proinflammatory cytokines, is also not considered. These soups could be quite tasty but may have excess of nutrients that are known to have adverse effects, with a lack of nutrients having beneficial effects. There is a need to develop a recipe with protective nutrients, which can be added to any of the standard soup recipes, to make them healthy soups. A recipe based on Mediterranean foods appears to solve this problem.

\section{FOOD INGREDIENTS OF A STANDARD SOUP}

Tomato soup (Serving per Recipe: $6-\mathrm{T}$ is a Tablespoon)

\begin{tabular}{|l|l|l|l|}
\hline Ingredients & $\begin{array}{l}\text { Weight } \\
(\mathrm{g})\end{array}$ & $\begin{array}{l}\text { Approx. } \\
\text { measures }\end{array}$ & Nutrient Information \\
\hline Butter & $30 \mathrm{~g}$ & $2 \mathrm{~T}$ & $\begin{array}{l}\text { Cholesterol, Saturated fat, } \\
\text { Monounsaturated fat (MUFA), } \\
\text { Polyunsaturated fat (PUFA), Trans } \\
\text { fat, Vitamin A, Vitamin D, Vitamin E }\end{array}$ \\
\hline Onion & $40 \mathrm{~g}$ & $\begin{array}{l}1 \text { medium } \\
\text { chopped }\end{array}$ & $\begin{array}{l}\text { Quercetin, Dietary fiber, Vitamin B6, } \\
\text { Folate, Vitamin C, Potassium, } \\
\text { Manganese) }\end{array}$ \\
\hline $\begin{array}{l}\text { All purpose } \\
\text { flour }\end{array}$ & $15 \mathrm{~g}$ & $2 \mathrm{~T}$ & $\begin{array}{l}\text { Refined Carbohydrate rich, Low } \\
\text { dietary Fiber }\end{array}$ \\
\hline $\begin{array}{l}\text { Tomato } \\
\text { juice }\end{array}$ & $945 \mathrm{ml}$ & 1 quart & $\begin{array}{l}\text { Carotene, Lycopene, Vitamin C, } \\
\text { Fiber, Potassium }\end{array}$ \\
\hline Milk, cow's & $475 \mathrm{ml}$ & 2 cups & $\begin{array}{l}\text { Protein, Calcium, Saturated fat, } \\
\text { Cholesterol, Potassium, Sodium }\end{array}$ \\
\hline Salt to taste & & \\
\hline
\end{tabular}

Preparation: In an oven /stove, over medium heat, saute' onions in butter until translucent. Remove from the heat. Stir in the flour so that no lumps remain, then slowly whisk in the tomato juice. Return to the heat and add salt to taste. Cook until just boiling but turn off the heat before it boils. Let it cool for 10 minutes then slowly stir in milk. Serve immediately.

COST OF MATERIAL INR 9.00(US\$0.20) for per serving, sold in commercial restaurants approx. INR35.00(US\$0.70) per serving.

NUTRITIVE VALUE (per serving) OF THE FINISHED PRODUCT (Approximate)

\begin{tabular}{|l|l|}
\hline Energy Kcal / KJ & $119 \mathrm{Kcal} / 499.8 \mathrm{KJ}$ \\
\hline Total Fat & $5.6 \mathrm{~g}$ \\
\hline Cholesterol & $17 \mathrm{mg}$ \\
\hline Carbohydrates & $14.3 \mathrm{~g}$ \\
\hline Dietary fiber & $1 \mathrm{~g}$ \\
\hline Protein & $4.4 \mathrm{~g}$ \\
\hline Sodium & $494 \mathrm{mg}$ \\
\hline
\end{tabular}

\section{MEDITERRANEAN SOUP}

There is evidence that tomatoes are a rich source of vitamin C, lycopine, carotene, potassium and fiber. Tomatoes also contain a factor which has antiplatelet effects. Almonds and walnuts are rich in magnesium and arginine an amino acid which is a vasodilator. Arginine is the precursor of NO which protects the endothelium. Walnut is rich in alpha-linolenic acid (ALA) which may be protective against CVD, diabetes, obesity and degenerative brain diseases. Carrots and coriander leaves are rich in carotene and potassium. Columbus oil is a brand of olive oil and flax seed oil which is prepared to provide adequate monounsaturated fatty acids(MUFA), and a balanced ratio of w-6:w-3 fatty acids ( in a ratio of 1:1). Oxidized LDL antibodies (OLAB) have been shown, in studies, to protect against atherosclerosis. Scientists in five European countries working as part of the EUROLIVE Study Group designed a crossover study to see whether higher polyphenol levels in different olive olis would generate more OLABs. 200 healthy men were randomly assigned to consume, in three week stints, $25 \mathrm{~mL}$ a day (just under two tablespoons) of each of three olive oils with high, medium, and low phenolic content. The researchers found that the protective OLABs increased in direct relationship to the phenolic content of the olive oils [69]. This was the conclusion of researchers from the University of Bordeaux, who followed more than 7,000 older people (over the age of 65), in the French cities of Bordeaux, Dijon, and Montpellier, for more than five years. Compared to those who seldom or never used olive oil, those who consume plenty of olive oil during the five-year duration of the study may reduce their risk of stroke by as much as $2.6 \%$ to $1.5 \%$ - a $41 \%$ drop [70]. While almond is rich in MUFA, walnut is more rich in alpha-linolenic acid. Both the nuts are known to decrease proinflammatory cytokines; TNF-alpha, IL-6 and C-reactive proteins which are atherogenic and prothrombotic. Oleic acid (MUFA) is an essential fatty acid which causes increase in HDL-C and may have anti-inflammatory effects. Scientists in Barcelona and São Paulo, who conducted a recent cross-over study to compare the effects of virgin olive oil, almonds, and walnuts in lowering cholesterol in subjects with high cholesterol levels. Subjects ate a healthy "run in" diet for four weeks first, to put all participants at a similar starting place. Then, each person spent 4 weeks on each of three diets: one enriched with virgin olive oil (VOO), one enriched with walnuts, and one with almonds. LDL ("bad") cholesterol was reduced on average $7.3 \%, 10.8 \%$ and $13.4 \%$ after the VOO, walnut, and almond diets, respectively, with total cholesterol and LDL/HDL ratio improving similarly. Researchers concluded that all three of these healthy foods contribute to the heart-health benefits of the Mediterranean Diet [71].

\section{MEDITERRANEAN SOUP}

\begin{tabular}{|l|l|l|l|}
\hline Ingredients & $\begin{array}{l}\text { Weight } \\
(\mathrm{g})\end{array}$ & $\begin{array}{l}\text { Approx. } \\
\text { measures }\end{array}$ & Nutrient Information \\
\hline Tomatoes & $250 \mathrm{~g}$ & $\begin{array}{l}2-3 \text { medium } \\
\text { size }\end{array}$ & $\begin{array}{l}\text { Carotene, Lycopene, Vitamin C, } \\
\text { Fiber, Potassium, Tomato oil }\end{array}$ \\
\hline Raisins & $10 \mathrm{~g}$ & $2 \mathrm{tsp}$ & $\begin{array}{l}\text { Glucose, Calcium, Phosphorous, } \\
\text { Iron, Resveratrol }\end{array}$ \\
\hline
\end{tabular}


contd....

\begin{tabular}{|c|c|c|c|}
\hline Walnuts & $10 \mathrm{~g}$ & 2 nos. & Arginine, ALA, Magnesium, \\
\hline Almonds & $10 \mathrm{~g}$ & 8 nos. & Arginine, Oleic acid, Magnesium \\
\hline Carrots & $50 \mathrm{~g}$ & 1 medium size & Carotene, Potassium, Arginine \\
\hline \multicolumn{3}{|c|}{ Coriander leaves to taste } & Carotene, Potassium \\
\hline $\begin{array}{l}\text { Refined } \\
\text { mustard oil } \\
\text { or Columbus } \\
\text { oil }\end{array}$ & $10 \mathrm{~g}$ & 2 tsp & Omega-3,MUFA,Antioxidants \\
\hline \multicolumn{4}{|c|}{ Brown sugar to taste or more raisins } \\
\hline
\end{tabular}

COST OF MATERIAL INR 14.00(US\$ 0.35) for 2 cups(tea cups) of soup.

\section{PREPARATION:}

Make tomato purée with $250 \mathrm{~g}$ tomato and add desired water to make it 2 cups of soup.

(About $50 \mathrm{~g}$ carrots may be added in the mixer to make it more thick and nutritious).

Crush the almonds and walnuts into small pieces and add crushed raisins paste.

Finally add salt to taste, and grill the whole material in a cooker along with $10 \mathrm{~g}$ of Columbus oil.

\section{NUTRITIONAL PROFILE OF THE FINISHED PRODUCT (APPROXIMATE)}

\begin{tabular}{|l|l|}
\hline Energy,Kcal /KJ & $325 \mathrm{Kcal} / 1365 \mathrm{KJ}$ \\
\hline Total Carbohydrates & $27.8 \mathrm{~g}$ \\
\hline Total Proteins & $5.6 \mathrm{~g}$ \\
\hline Total Fat & $22.6 \mathrm{~g}$ \\
\hline SFA & $9.25 \mathrm{~g}$ \\
\hline MUFA & $10.27 \mathrm{~g}$ \\
\hline PUFA & $3.08 \mathrm{~g}$ \\
\hline Omega-3 fatty acids & $2.16 \mathrm{~g}$ \\
\hline Omega-6 fatty acids & $0.92 \mathrm{~g}$ \\
\hline w-6/w-3 ratio & 0.042 \\
\hline Cholesterol & Nil \\
\hline Fiber & $0.66 \mathrm{~g}$ \\
\hline Arginine & $273 \mathrm{mg}$ \\
\hline Threonine & $340 \mathrm{mg}$ \\
\hline Total minerals & $0.78 \mathrm{~g}$ \\
\hline Magnesium & \\
\hline Potassium & $200 \mathrm{mg}$ \\
\hline Cu, Zn, Mn & \\
\hline $\begin{array}{l}\text { Sodium (would depend on } \\
\text { added salt say } 0.5 \mathrm{~g})\end{array}$ & \\
\hline
\end{tabular}

\section{HEALTH CLAIMS OR PARALLEL HEALTH ASSERTIONS}

Acute coronary syndromes, chronic CAD, angina pectoris, stroke, diabetes mellitus, obesity, metabolic syndrome, glucose intolerance, rheumatoid arthritis, asthma, depression, autoimmune diseases, and degenerative diseases of the brain.

\section{CONCLUSION}

Lifestyle interventions, particularly changes in diet and increases in physical activity, are established methods to prevent metabolic syndrome and, consequently, to reduce the likelihood of cardiovascular disease and diabetes. The Mediterranean diet is generally considered to consist of a high concentration of good oils (monosaturated fatty acids), usually from olives and olive oil; daily consumption of fruit, vegetables, wholegrains and low-fat dairy; weekly fish, poultry, nuts and legumes; low red meat consumption and moderate alcohol consumption. It has been linked to reduced risk of cardiovascular disease, cancer and diabetes. Evidence suggests that the Mediterranean diet could serve as an anti-inflammatory dietary pattern, which could help to fight diseases related to chronic inflammation, including metabolic syndrome. This new review did not assess the development of heart disease and diabetes, but it has demonstrated that the Mediterranean diet reduces the development of metabolic syndrome and its components, which are often precursors to the development of these conditions. Overall, this research review provides further evidence of the benefits of eating a Mediterranean-style diet and quantifies the benefit in terms of the individual risk components of metabolic syndrome.

\section{CONFLICT OF INTEREST}

Declared none.

\section{ACKNOWLEDGEMENTS}

Acknowledgements are due to International College of Nutrition for providing the logistic support.

\section{REFERENCES}

[1] Simopoulos AP. Importance of the ratio of omega-6/omega-3 essential fatty acids: evolutionary aspects. In: Simopoulos AP and Cleland LG, Eds. Omega-6/omega-3 essential fatty acid ratio: the scientific evidence. World review of nutrition and dietetics. Basel: Karga Publishers 2003; pp. 1-19.

[2] DeMeester F. Wild-type land based food in health promotion and disease prevention, The Columbus Concepty. In: De Meester F, Watson RR, Eds. Wild type food in health promotion and disease prevention. Totova, NJ: Humana Press 2008; pp. 3-20.

[3] Katcher HI, Legro RS, Kunselman AR, et al. The effects of whole grain- enriched hypocaloric diet on cardiovascular disease risk factors in men and women with metabolic syndrome. Am J Clin Nutr 2008; 87: 79-90.

[4] Singh RB, DeMeester F, Mechirova V, Pella D, Otsuka K. Fatty acids in the causation and therapy of metabolic syndrome. In: DeMeester F, Watson RR, Eds. Wild type foods in health promotion and disease prevention. NJ: Humana Press 2008; pp. 263-84.

[5] Singh RB, Fedacko J, Pella D, et al. Prevalence and risk factors of prehypertension and hypertension in five Indian cities. Acta Cardiol 2011; 66: 29-37.

[6] Hu FB, Stampfer MJ. Nut consumption and risk of coronary heart disease: a review of epidemiologic evidence. Curr Athero reports 1999; 1: 204-9. 
[7] Jenkins DJA, Kendall CWC, Marchie A, et al. Dose response of almonds, on coronary heart disease risk factors: blood lipids, oxidized low density lipoproteins,lipoprotein(a),homocystein, and pulmonary nitric oxide, a randomized, controlled, crossover trial. Circulation 2002; 106: 1327-32.

[8] Sabate J, Fraser GE, Burke K, et al. Effects of walnuts on serum lipid levels and blood pressure in normal men. N Engl J Med 1993; 328: 603-7.

[9] Abbey M, Noakes M, Belling GB, et al. Partial replacement of saturated fatty acids with almonds or walnuts lowers total plasma cholesteroland low density lipoprotein cholesterol. Am J Clin Nutr 1994; 59: 995-9.

[10] Singh RB, DeMeester F, Pella D, et al. Globalisation of dietary wild foods protects against cardiovascular disease and all cause moratlities? a scientific statement from the international college of cardology, columbus paradigm institute and international colege of nutrition. Open Nutra J 2009; 2: 42-5.

[11] Knoops KTB, de Groot LC, Kromhout D, et al. Mediterranean diet, lifestyle factors and 10-year mortality in elderly European men and women. The HALE project. JAMA 2004; 292: 1433-9.

[12] Trichopoulou A, Costacou T, Bamia C, Trichopoulos D. Adherence to a Mediterranean diet and survival in a Greek population. N Engl J Med 2003; 348: 2599-608.

[13] De Logeril M, Salen P, Martin JL, Monjaud I, Delaye J, Mamelle N. Mediterranean diet, traditional risk factors and the rate of cardiovascular complications after myocardial infarction. Final report of the Lyon Diet Heart Study. Circulation 1999; 99: 779-85.

[14] Singh RB, Dubnov G, Niaz MA, et al. Effect of an IndoMediterranean diet on progression of coronary disease in high risk patients: a randomized single blind trial. Lancet 2002; 360: 1455-61.

[15] Singh RB, Rastogi SS, Verma R, et al. An Indian experiment with nutritional modulation in acute myocardial infarction. Am J Cardiol 1992; 69: 879-85.

[16] Singh RB, Niaz MA, Kartik C. Can n-3 fatty acids provide myocardial protection be decreasing infarct size and inhibiting atherothrombosis? Eur Heart J 2001; 3(Suppl. D): 62-9.

[17] Singh RB, Pella D, DeMeester F. What to eat and chew in acute myocardial infarction. Eur Heart J 2006; 27: 1628-9.

[18] Harper CR, Jacobson TA. Usefulness of omega-3 fatty acids and the prevention of coronary heart disease. Amer J Cardiol 2005; 96 : 1521-9.

[19] Harris WS, Reid KJ, Sands SA, et al. Blood omega-3 and trans fatty acids in middle aged acute coronary syndrome patients. Am J Cardiol 2007; 99: 154-8.

[20] Singh RB, Pella D, Sharma JP, et al. Increased concentrations of lipoprotein(a), circadian rhythms and metabolic reactions, evoked by acute myocardial infarction in relation to large breakfast. Biomed Pharmacother 2004; 58(Suppl): 116-21.

[21] Ailhaud G, Massiéra F, Weill P, Legrand P, Alessandri JM, Guesnet P. Temporal changes in dietary fats: role of $n-6$ polyunsaturated fatty acids in excessive adipose tissue development and relationship to obesity. Prog Lip Res 2006; 45: 203-36.

[22] Rolland-Cachera MF, Maillot M, Deheeger M, Bellisle F. Prediction of adult adiposity using two indicators: a 20 year followup study. Int J Obes 2006; 30: S12.

[23] Singh RB, Rastogi SS, Verma R, et al. Randomized, controlled trial of cardioprotective diet in patients with acute myocardial infarction: results of one year follow up. BMJ 1992; 304: 1015-9.

[24] Singh RB, Pella D, Kartikey K, et al. Prevalence of obesity, physical inactivity and undernutrition, a triple burden of diseases, during transition in a middle income country. Acta Cardiol 2007; 62: 119-27.

[25] Esposito K, Marfella R, Ciotola M, et al. Effect of a Mediterranean-style diet on endothelial dysfunction and markers of vascular inflammation in the metabolic syndrome: a randomized trial. JAMA 2004; 292: 1440-6.

[26] Lteif AA, Han K, Mather KJ. Obesity, insulin resistance, and the metabolic syndrome: determinants of endothelial dysfunction in whites and blacks. Circulation 2005; 112: 32-8.

[27] Hamburg NM, Larson MG, Vita JA, et al. Metabolic syndrome, insulin resistance, and brachial artery vasodilator function in framingham offspring participants without clinical evidence of cardiovascular disease. Am J Cardiol 2008; 101: 82-8.

[28] DeSouza CA, Shapiro LF, Clevenger CM, et al. Regular aerobic exercise prevents and restores age-related declines in endothelium- dependent vasodilation in healthy men. Circulation 2000; 102: 1351-7.

[29] Lecour S, James RW. When are proinflammatory cytotoxic SAFE in heart failure. Eur Heart J 2011; 32(6): 680-5.

[30] Weissmann G. Virgin olive oil and Mediterranean Diet fight Heart Disease by changing our gene function. Science Daily pub: FSAEB J 2010.

[31] Kromhout D, Yasuda S. Fish oil and Omega -3 Fatty acids in cardiovascular disease: do they really work. Eur Heart J 2012; 33(4): 436-43.

[32] Simopoulus AP. Omega -3 Fatty Acids and cardiovascular disease: the epidemeological evidence. Environ Health Prev Med 2002; 6(4): 203-9.

[33] Psota TL, Gebaur SK, Kris-Etherton P. Dietary w-3 fatty acid intake and cardiovascular risk. Am J Cardiol 2006; 98(4A): 3i- 8i.

[34] Mozaffarian D, Geelan A, Brouwer IA, et al. Effect of fish oil on heart rate in humans, a metaanalysis of randomized, controlled trials. Circulation 2005; 112: 1945-52.

[35] George EB, Williams SH. Effect of dietary omega-3 fatty acids on the heart rate and the heart rate variability responses to myocardial ischemia or submaximal exercise. AJP-Heart 2011; 300(6): H2288-99.

[36] Iso H, Kobayashi M, Ishihara J, et al. Intake of Fish and n3 Fatty Acids and Risk of Coronary Heart Disease Among Japanese: The Japan Public Health Center-Based (JPHC) Study Cohort I. Circulation 2006; 113: 195-202.

[37] Seremi A, Arora R. Utility of omega-3 Fatty Acids in cardiovascular disease. Am J Ther 2009; 16(5): 421-36.

[38] DeLeiris J, De lorgeril M, Boncher F. Fish oil and Heart Health. J Cardiovasc Pharmacol.2009; 54(5): 378-84.

[39] Holy EW, Foriester M, Ritcher EK, et al. Dietary (alpha) Linolenic acid Inhibits arterial Thrombus formation, tissue factor expression and platelet activation 2011. Arteroscler Thromb Vasc Bio 2011; 31(8): 1772-80.

[40] Singh RB, Niaz MA, Agarwal P, Beegum R, Rastogi SS. Effect of antioxitant rich foods on plasma ascorbic acid, cardiac enzyme and lipid peroxide levels in patients hospitalized with acute myocardial infarction. J Am Diet Assoc 1995; 95: 775-80.

[41] Singh RB, Niaz MA, Sharma JP, et al. Randomized, double blind, placebo controlled trial of fish oil and mustard oil in patients with suspected acute myocardial infarction: the Indian Experiment of Infarct Survival-4. Cardiovasc Durg Ther 1997; 11: 485-91.

[42] Estruch R, Martinez-Gonzalez MA, Corella D, et al. Effects of Mediterranean-style diet on cardiovascular risk factors,a randomized trial. Ann Intern Med 2006; 145: 1-11.

[43] De Lorgeril M, Salen P. The Mediterranean-style diet for the prevention of cardiovascular diseases. Pub Health Nutr 2006; 9: 118-23.

[44] Gramenzi A, Gentile A, Fasoli M, et al. Association between certain foods and risk of acute myocardial infarction in women. BMJ 1990; 300: 771-3.

[45] Diamant M, Lamb HJ, van de Ree MA, et al. The association between abdominal visceral fat and carotid stiffness is mediated by circulating inflammatory markers in uncomplicated type 2 diabetes. J Clin Endocrinol Metab 2005; 90: 1495-501.

[46] Piche ME, Lemieux S, Weisnagei SJ, Corneau L, Nadeau A, Bergeron J. Relation of high-sensitivity C-reactive protein, interleukin-6, tumor necrosis factor alpha and fibrinogen to abdominal adipose tissue, blood pressure and cholesterol and triglyceride levels in healthy postmenopausal women. Am J Cardiol 2005; 96: 92-7.

[47] Pereira MA, Kartashow AI, Ebbeling CB, et al. Fast-food weight gain and insulin resistance (the CARDIA study): 15-year prospective analysis. Lancet 2005; 365: 36-42.

[48] Drapeau V, Despres JP, Bouchard C, et al. Modifications in foodgroup consumption are related to long-term body-weight changes. Am J Clin Nutr 2004; 80: 29-37.

[49] Nordmann AJ, Suter-Zimmermann K, Bucher HC, et al. Metaanalysis comparing Mediterranean to low fats for modification of cardiovascular risk factors. Am J Med 2011; 124(9): 841-51.

[50] Alvarez León EE, Henríquez P, Serra-Majem L. Mediterranean Diet and Metabolic Syndrome: A cross-sectional study in Canary islands. Public Health Nutr 2006; 9(8A): 1089-98.

[51] Babio N, Bulló M, Salas-Salvadó J. Mediterranean Diet and metabolic syndrome: the evidence. Public Health Nutr 2009; 12(9a): 1607-17. 
[52] Rumawas ME, Meigs JB, Dwyer JT, McKeown NM, Jacques PF. Mediterranean -Style dietary pattern, reduced risk of metabolic syndrome traits and incidence in Framingham Offspring Cohort. Am J Clin Nutr 2009; 90(6): 1608-14.

[53] Teresa TF, Katyhyn MR, Mantzoros CS, et al. Mediterrenean diet and incidence of and mortality from coronary heart disease in women. Circulation 2009; 119: 1093-100.

[54] Kastorni CM, Millionis H, Esposito K, et al. The effect of mediterranean diet on metabolic syndrome and its components. J Am Coll Cardiol 2011; 57(11): 1299-313.

[55] Singh RB, DeMeester F, Pella D, et al. Globalisation of Dietary wild food protects against cardiovascular disease and all causes mortalities? A scientific statement from the International College of cardiology, Columbus Paradigm Institute and International college of Nutrition. Open Nutra J 2009; 2: 42-5.

[56] Singh RB, De Meester F, Juneja L, Mechirova V, Pella D. New risk factors of heart failure? Euro Heart J 2007; 8: 1038-9.

[57] Patricia Mediterranean diet linked to healthy Lifestyle and reduced mortality. J Am Coll Cardiol 2011.

[58] A Strict Mediterranean Diet can help reduce deaths fromm major chronic disease 2010. From escience.com. Health and Medicine 2008; 17(24): 07 EDT.

[59] Sofi F, Abbate R, Gensini GF, et al. Acrruing evidence on benefits of adherence to the Mediterranean diet on Health: an updated systematic review and meta-analysis. Am J Clin Nutr 2010; 92(5): 1189-96.

[60] Stephen E, Chiuve scD, Teresa T, et al. Adherence to a low-risk, healthy lifestyle and risk of sudden cardiac death among women. JAMA 2011;306(1): 62.

[61] Escurniol V, Cofán M, Serra M, et al. Serum sterol response to increasing plant sterol intake from natural foods in the Mediterranean diet. Eur J Nutr 2009; 48(6): 373-82.
[62] Wolf E, Vergnes MF, Portugal H, et al. Cholesterol -absorbers Status Modifies the LDL cholesterol -Lowering effect of a Mediterranean -Type diet in Adults with moderate cardiovascular risk factors. J Nutr 2011; 141(10): 1791-8.

[63] Chrysohosu C, Pangiotakes DB, Aggelopolos P, et al. The Mediterranean Diet contributes to the preservation of left ventricular systolic function and to the long- term favourable progress of patients who have had an acute coronary events. Am J Clin Nutr 2010; 92:147-54.

[64] Kelly DS, Branch LB, Love JE, et al. Dietary alpha-linolenic acid and immunocompetence in humans. Am J Clin Nutr 1991; 53 40-6.

[65] Caughey GE, Mantzioris E, Gibson RA, Cleland LG, James MJ. The effect on human tumor necrosis factor-alpha and interleukin1 beta production of diets enriched in w-3 fatty acids from vegetable oil or fish oil. Am J clin Nutr 1996; 63: 116-22.

[66] Thies F, Nebe-von-Caron G, Powell JR, et al. Dietary supplementation with gama-linolenic acid or fish oil decreases $\mathrm{T}$ lymphocyte proliferation in healthy older humans. J Nutr 2001; 131: 1918-27.

[67] Lloyd-Jones D, Adams RJ, Brown TM, et al. Heart disease and stroke statistics-2010 update: A report from the American Heart Association. Circulation 2010; 121(7): e46-215.

[68] Sabate J, Ang Y. Nuts and health outcomes: New epidemiological evidence. Am J Clin Nutr 2009; 89(5): 1643S-8S.

[69] High-phenolic olive oil protects arteries best. Clin Nutr 2011 [Epub ahead of print].

[70] Olive oil may be protective against strokes. Neurology 2011. [Epub ahead of print]

[71] Olive oil, almonds or walnuts? All of the Above. Nutr Metab Cardiovasc Dis 2011 [Epub ahead of print]

This is an open access article licensed under the terms of the Creative Commons Attribution Non-Commercial License (http://creativecommons. org/licenses/ by-nc/3. 0/) which permits unrestricted, non-commercial use, distribution and reproduction in any medium, provided the work is properly cited. 